\title{
The Effect of Deal Knowledge on Consumer Purchase Behavior
}

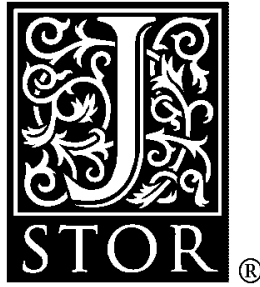

\author{
Aradhna Krishna
}

Journal of Marketing Research, Vol. 31, No. 1. (Feb., 1994), pp. 76-91.

Stable URL:

http://links.jstor.org/sici?sici=0022-2437\%28199402\%2931\%3A1\%3C76\%3ATEODKO\%3E2.0.CO\%3B2-7

Journal of Marketing Research is currently published by American Marketing Association.

Your use of the JSTOR archive indicates your acceptance of JSTOR's Terms and Conditions of Use, available at

http://www.jstor.org/about/terms.html. JSTOR's Terms and Conditions of Use provides, in part, that unless you have obtained prior permission, you may not download an entire issue of a journal or multiple copies of articles, and you may use content in the JSTOR archive only for your personal, non-commercial use.

Please contact the publisher regarding any further use of this work. Publisher contact information may be obtained at http://www.jstor.org/journals/ama.html.

Each copy of any part of a JSTOR transmission must contain the same copyright notice that appears on the screen or printed page of such transmission.

The JSTOR Archive is a trusted digital repository providing for long-term preservation and access to leading academic journals and scholarly literature from around the world. The Archive is supported by libraries, scholarly societies, publishers, and foundations. It is an initiative of JSTOR, a not-for-profit organization with a mission to help the scholarly community take advantage of advances in technology. For more information regarding JSTOR, please contact support@jstor.org. 
ARADHNA KRISHNA

\begin{abstract}
Research has shown that there is heterogeneity in consumer knowledge of prices and deals. In addition, it has been found that buyers' purchase behavior can be influenced not only by the current price of a product, but also by what prices they expect in the future. The author builds a purchase quantity model to contrast normative behavior of consumers who have knowledge of future price deals with that of those who do not. Implications from the model are derived concerning consumer deal response for the consumer's preferred and less preferred brands. These implications show that normative purchase behovior is very different between consumers with and without knowledge of future deals. The model implies that consumers with knowledge of future deals could be more likely to purchase on low-value deals and deals on less preferred brands compared with consumers without knowledge of future deals. Another implication of interest is that the relative quantity purchased by consumers who have deal knowledge compared with those who do not depends on the time pattern of deals. The implications are supported in a laboratory experiment. The author finds that actual behavior varies depending on deal knowledge and is quite consistent with model predictions.
\end{abstract}

\title{
The Effect of Deal Knowledge on Consumer Purchase Behavior
}

Observational studies show that there is heterogeneity among consumers in how much they think about prices and deals (Dickson and Sawyer 1990). Some people check prices and note deals all the time, whereas others apparently do not. Arguably, the former are consumers who might acquire deal knowledge over time, whereas the latter would not. This is corroborated by research showing high variance in consumer knowledge of prices (Dickson and Sawyer 1990) and deals (Krishna, Currim, and Shoemaker 1991). It also has been found that buyers' purchase behavior can be influenced not only by the current price of a product, but also by what prices they expect in the future (Jacobson and Obermiller 1990; Kalwani and Yim 1992; Winer 1985). I investigate how het-

Aradhna Krishna is an Associate Professor, Graduate School of Business, Columbia University. The author thanks Imran Currim, Don Lehmann, and Bob Shoemaker for their continued support throughout this project. John Lynch provided guidance in designing the experiment. Bruce Buchanan, Kim Corfman, Bob Meyer, Ambar Rao, Dave Schmittlein, Joel Steckel, and the JMR reviewers and editor gave many valuable suggestions. erogeneity in deal knowledge among consumers is likely to affect their response to deals.

Some ways in which deal knowledge can alter consumer purchase behavior are exemplified in the following scenarios: If some consumers expect their favorite brand of paper towel to be offered on deal next week, whereas others do not, then the former group could buy a smaller quantity of a less preferred brand on deal today compared with the second group. Similarly, if a retailer offers a brand at a $20 \%$ markdown every four weeks and currently is offering only a $10 \%$ markdown, consumers who expect a $20 \%$ markdown every four weeks could buy a smaller quantity on deal today.

We build a normative purchase quantity model that incorporates consumer knowledge of future deals. The model fits into a stream of economic order quantity (EOQ) models in the marketing literature that determine optimal purchase quantity for the buyer under different scenarios (Armstrong, Bass, and Rao 1991; Blattberg, Eppen, and Lieberman 1981; Umesh 1989). Using an EOQ model, Blattberg, Eppen, and Lieberman (1981) present an explanation for price promotions based on the idea of transferring inventory carrying costs from the retailer to the 
consumer. Umesh (1989) extends this work to allow for different purchase behavior of deal-prone and non-dealprone consumers. Armstrong, Bass, and Rao (1991) study not only deals from the retailer to the consumer but also trade deals from the manufacturer to the retailer. They determine when a retailer should accept trade promotion allowances offered by a retailer and when they should pass through a large part of this allowance to the consumer.

The model proposed here predicts normative consumer behavior when consumers have versus do not have knowledge of future deals. Implications from the model contrast deal response of consumers with and without knowledge of future deals for their preferred and less preferred brands. We test in a laboratory experiment whether aware and unaware consumers exhibit differences across different dealing patterns and if they behave according to model predictions. Tests of normative models are rare in the literature (Meyer 1991, p. 2). We concentrate on the consumer decision, and do not consider the retailer decision.

The normative model is described in the next section, followed by model implications. Then we present the empirical support for the model implications and end with the managerial implications and conclusions of the study.

\section{PURCHASE QUANTITY MODEL}

\section{Overview}

The model determines purchase quantity of a product class for a specific consumer on a specific purchase occasion. This is the quantity the consumer should purchase if he or she wants to minimize his or her expenditure for the product class. The model allows for consumer knowledge of future deals and also for multiple brands.

Consumers with knowledge of future deals. These consumers know when future deals on a brand will be offered and what the price on these deals will be. This type of consumer may not be uncommon-for example, Krishna, Currim, and Shoemaker (1991) found that for some brand-sizes, about a fifth of the product class buyers had reasonably accurate knowledge about deal price, regular price, and deal frequency. One would expect consumers to have better knowledge of deal timing when deals occur regularly (as I found for Coke and Pepsi ${ }^{1}$ ) or nearly regularly (as I found for Palmolive dishwashing detergent, Crest toothpaste, and Charmin bathroom tissue).

Consumers without knowledge of future deals. These consumers are assumed to have no idea about when the next deal will occur. We assume that these consumers do not consider future deals in their purchase decision.

\footnotetext{
${ }^{1}$ I collected data for 20 weeks in a New York supermarket, and it showed that deals occurred two weeks apart for Coke and Pepsi, between three and six weeks apart for Palmolive and Crest, and between three and five weeks apart for Charmin.
}

Such consumers were found in past research (Krishna, Currim, and Shoemaker, 1991), in which, across nine brand-sizes, on average, more than a quarter of the product class buyers had no idea about the deal frequency of a brand-size.

Other types of consumers include those with inaccurate expectations, who have a mistaken expectation of when the next deal will occur. Though the model extends to these types of consumers as well, they are not the focus of this research. Here, consumers with deal knowledge are referred to as "aware consumers" or "awares," and consumers without deal knowledge as "unaware consumers" or "unawares."

Assumptions. We assume that all consumers are rational and want to minimize their cost, given whatever information they have. Therefore, even though unaware consumers have no knowledge of future deals, they purchase on deals if they happen on them. We also assume that consumers go to the store each week, so that the transaction cost for a specific product class is zero. This has been shown to be consistent with the shopping behavior of many individuals (Kahn and Schmittlein 1989). In addition, we assume that holding cost is a linear function of inventory and is the same for all brands. There could be many reasons why buyers may not hold large stocks of a good, for example, a maximum storage capacity level, fear of spoilage, and opportunity cost of space. The linear holding cost function is simply a rough approximation of these influences.

For analytical tractability and ease of exposition, we also assume that quantities purchased are perfectly divisible, the household's consumption rate is constant, and the regular price of the brand is stable over the term considered. The assumption of perfectly divisible quantities is not restrictive and simplifies the mathematics. Relaxing the assumption would mean that consumers would have to buy smaller or larger than optimal quantities. With most goods being available in multiple package sizes, this change in purchase quantity need not be exceedingly large. A constant consumption rate assumption can be reasonable for many goods, for example, paper towels. The regular price for most goods should be stable over the medium term.

\section{Model Constructs}

The model is developed at the individual level, but the individual subscript is not shown for simplicity. The variables used are:

$$
\begin{aligned}
I_{t} & =\text { Inventory at time } t \\
U_{i} & =\text { non-price utility per unit of brand } i \\
U^{*} & =\text { non-price utility per unit of the favorite brand } \\
S C_{i} & =\text { Substitution cost for brand } i \text { per unit of prod- } \\
& \text { uct. } \\
R & =\text { Regular (nondeal) price of the consumer's } \\
& \text { preferred (or favorite) brand } \\
R_{i} & =\text { Regular (nondeal) price for brand } i \\
S_{i, t} & =\text { price of brand } i \text { at time } t
\end{aligned}
$$


$S_{i, t}^{k_{\text {(exp) }}}=$ Expected deal price on the $k^{\text {th }}$ expected deal for brand $i$ after time $t$; hence, $S_{i, t}^{2}$ is the expected deal price for brand $i$ on the second expected deal beyond time $t$

$T_{i, t}^{k_{(\exp )}}=$ Expected time to the $k^{\text {th }}$ expected deal on brand $i$ after time $t$

$h=$ Holding cost per standard unit of a product per unit time (e.g., per week).

$c=$ Consumption rate in units of product per unit time

$q_{i, t}=$ Quantity of brand $i$ purchased at time $t$; the dependent variable.

We assume that $S_{i, t}^{k_{(\exp )}}$ and $T_{i, t}^{k_{(\exp )}}$ are deterministic. This is a simplification. We could allow $S_{i, t}^{k_{\text {(exp) }}}$ and $T_{i, t}^{k_{(\exp )}}$ to have a probability distribution, but this would make the mathematics less tractable. Many prior researchers also have used point estimates to model consumer expectations of prices (see Gurumurthy and Little 1987; Lattin and Bucklin 1989; Winer 1986). In addition, simple knowledge of prices as represented in point estimates may not be uncommon. For example, in a survey to determine consumer knowledge of normal (modal) prices for grocery products, Urbany and Dickson (1991, p. 48) gave consumers a dollar scale to indicate a range of normal prices. They found that 'despite the interviewers' explanation and emphasis on the use of the dollar scale to indicate a range of normal prices, 57 percent of the time respondents reported Normal Price Estimates as price points rather than as ranges."

Multiple brands are incorporated in the model by substitution costs. The nonprice utility (i.e., utility not taking price into account) per unit of brand $i$ is denoted by $U_{i}$. The nonprice utility for the favorite brand is denoted by $U^{*}$. We define substitution cost per unit of brand $i$ as $U^{*}-U_{i}$. Therefore, the substitution cost for brand $i$ $\left(S C_{i}\right)$ is the decrease in utility from consuming one unit of brand $i$ instead of one unit of the preferred (or favorite) brand. The concept of substitution costs for less preferred brands is not new (see Pessemier 1959). We assume that the lower utility that a buyer gets from purchasing a less preferred brand is reflected in an increase in the "price" of the less preferred brand. This increase in price (substitution cost) equals the minimum difference between the prices of the two brands so that consumers of one brand switch to the other brand. The approach is similar to that taken by other researchers (Krishna 1992; Narasimhan 1988; Raju, Srinivasan, and Lal 1990).

Unaware consumers need not know the actual discount $\left(R_{i}-S_{i, t}\right)$, either. The model applies even in cases in which $R_{i}-S_{i, t}$ is not the actual deal amount but what these consumers perceive the deal amount to be. Therefore, unaware consumers could be reacting to the fact that something is on deal without noting the actual deal amount. We first derive the optimal purchase quantity for unaware consumers and then for aware consumers.

\section{Optimal Purchase Quantity for Unaware Consumers}

Unaware consumers are assumed not to take future deals into account. In determining optimal purchase quantity, the consumer should contrast any savings in purchase cost that the current deal offers with the additional holding cost he or she incurs by purchasing larger quantities on deal. If the consumer purchases on a deal for a less preferred brand because of the price discount, he or she also needs to take into account the loss in brand preference. Hence, savings in purchase cost take into account both the deal amount and the brand preferences (reflected in substitution cost). Holding cost for the additional inventory is made up of two elements: First, there is the cost of holding the total amount of inventory that the consumer has after the deal purchase; however, from this amount we also must deduct the cost of holding inventory that the consumer had before the purchase, because this cost would have been incurred anyway.

The total cost for the consumer is given in the expression in Figure 1.

Holding cost. The first term under holding cost is the cost of holding the total amount of inventory that the consumer has after the deal purchase, until this inventory is exhausted. If the consumer's inventory at time $t$ is $I_{t}$ and purchase quantity equals $q_{i, t}$, then the consumer's total inventory after purchase equals $I_{t}+q_{i, t}$. This amount of inventory will be depleted after $\left(I_{t}+q_{i, t}\right) / c$ periods. The number of units held in stock will successively decrease at the consumption rate. Because the consumer starts with $I_{t}+q_{i, t}$ units and consumes $c y$ units by time $y$, he or she will have inventory equalling $I_{t}+q_{i, t}-c y$ at time $y$. The holding cost integrates the cost of holding inventory that is in stock at each point in time from after the deal purchase (when the consumer has consumed zero inventory from the stock after purchase) until he or she has exhausted the entire inventory $\left(=\left(I_{t}+q_{i, t}\right) / c\right)$.

The second term is the cost of holding the inventory that the consumer had before the deal purchase, until this inventory is exhausted. It is computed in a similar manner. Therefore, the difference between the first and second terms reflects incremental holding costs due to the deal purchase.

Savings in purchase cost. Surplus s $_{i}$ per unit of brand $i$ is defined as the regular price per unit of brand $i$ adjusted for the nonprice utility of brand $i=R_{i}-U_{i}$. If there is no deal for any brand, the consumer buys the brand with the greatest surplus, that is the brand with the highest $R_{i}$ $-U_{i}$. This is the brand we define as the favorite brand, ${ }^{2}$ and we denote its regular price by $R$ and its nonprice

\footnotetext{
${ }^{2}$ The brand that consumers purchase when no other brand is on deal is assumed to have $S C_{i}=0$ and also is assumed to be their favorite brand. However, this need not be the consumer's actual favorite brand. There could be other brands that the consumer prefers but cannot afford in the absence of deals. These brands can be accommodated in the model by having a negative $S C_{i}$. In the absence of deals, these brands would not be purchased. However, with deals, they could be purchased.
} 
Figure 1

TOTAL COST FOR THE CONSUMER

$$
\begin{aligned}
& \text { Total cost (TC) }=\left[h \int_{0}^{\left(l_{t}+q_{i, t}\right) / c}\left(I_{t}+q_{i, t}-c y\right) d y\right]-\left[h \int_{0}^{l_{t} / c}\left(I_{t}-c y\right) d y\right]-\left[\left(R-S_{i, t}-S C_{i}\right) q_{i, t}\right] \\
& \begin{array}{l}
\begin{array}{c}
\text { Holding cost after } \\
\text { today's purchase }
\end{array} \text { no purchase today }
\end{array} \\
& \text { Incremental holding cost of } \\
& \text { today's purchase }
\end{aligned}
$$

\author{
Savings in \\ purchase cost \\ Savings in \\ purchase cost
}

utility per unit by $U^{*}$. Because substitution cost per unit of brand $i$ is $U^{*}-U_{i}$, the substitution cost for the favorite brand, by definition, is 0 .

When a deal is offered for brand $i$ at time $t$, one needs to compare the deal discount for brand $i$ at time $t$ with the regular price of the favorite brand (i.e., $R-S_{i, t}$ ), and adjust it for the substitution cost of brand $i$. Therefore, one needs to see $R-S_{i, t}-S C_{i, t} . R-S_{i, t}-S C_{i}$ is denoted by DealSavings $s_{i, t}$. Savings in purchase cost for a transaction equals DealSavings $s_{i, t}$ times the number of units purchased. The consumer should purchase a brand with the largest DealSavings ${ }_{i, t}$. DealSavings $_{i, t}$ are 0 for the favorite brand when it is not on deal, because $R=S_{i, t}$ and $S C_{i}=0$. Hence, a brand will not be purchased unless its DealSavings $s_{i, t} \geq 0$.

Optimal purchase quantity. This is computed by minimizing total cost as given in Figure 1. We first integrate Figure 1, which yields

$$
\begin{aligned}
T C= & {\left[h I_{t}\left(I_{t}+q_{i, t}\right) / c\right]+\left[h q_{i, t}\left(I_{t}+q_{i, t}\right) / c\right] } \\
& -\left[h\left(I_{t}+q_{i, t}\right)^{2} / 2 c\right]-\left[h I_{t}^{2} / c\right] \\
& +\left[h I_{t}^{2} / 2 c\right]-\left[\left(R-S_{i, t}-S C_{i}\right) q_{i, t}\right] .
\end{aligned}
$$

On simplification this reduces to

$$
\begin{aligned}
T C= & {\left[h q_{i, t} I_{t} / c\right]+\left[h q_{i, t}^{2} / 2 c\right] } \\
& -\left[\left(R-S_{i, t}-S C_{i}\right) q_{i, t}\right] .
\end{aligned}
$$

We have to minimize total cost with respect to $q_{i, t}$ subject to the constraint that $q_{i, t}+I_{t} \geq c$. This constraint implies that one must have enough stock after purchase (stock after purchase $=q_{i, t}+I_{t}$ ) to cover consumption in period $t(=c)$. Minimizing total cost $(T C)$ with respect to $q_{i, t}$ implies that $d T C / d q_{i, t}=0$, provided that a unique minimum exists for $0 \leq q_{i, t}<\infty$. Differentiating $T C$ with respect to $q_{i, t}$ yields

$$
\begin{gathered}
d T C / d q_{i, t}=\left[I_{t} h / c\right]+\left[h q_{i, t} / c\right] \\
\quad-\left[R-S_{i, t}+S C_{i}\right]=0, \text { or } \\
q_{i, t}^{*}=\left[\left(R-S_{i, t}-S C_{i}\right) c / h\right]-I_{t} \\
=\text { optimal purchase quantity for unawares. }
\end{gathered}
$$

Second-order conditions hold because $h / c>0$. We thus have located a unique minimum for the total cost function with respect to the quantity purchased.

The time to exhaust the inventory after purchase at time $t$ is given by the ratio of inventory after purchase and consumption rate and is denoted by $T_{t}^{*}$.

$$
T_{t}^{*}=\left(q_{i, t}^{*}+I_{t}\right) / c
$$

Note that the time to exhaust the total inventory after purchase is insensitive to the size of the current inventory, because $q_{i, t}^{*}=\left[\left(R-S_{i, t}-S C_{i}\right) c / h\right]-I_{t}$, and hence $T_{t}^{*}=\left(R-S_{i, t}-S C_{i}\right) / h$. Therefore, if two people with identical brand preferences started with different initial inventories, the two should end up with the same total inventories after a deal purchase.

The quantity up to which the unaware consumer brings his inventory when he or she makes a purchase $=q_{i, t}+$ $I_{t}=\left(R-S_{i, t}-S C_{i}\right) c / h$. For purposes of notation, this quantity is called $Q_{i, t}$. This notation is used subsequently.

\section{Optimal Purchase Quantity for Aware Consumers}

A consumer's expectations of future deals should affect his or her quantity decision if a deal is expected before he or she can exhaust the quantity that he or she would have purchased in the absence of future deals expectations, that is,

$$
T_{e, t}^{k_{(e x p)}}<T_{t}^{*}
$$

and it offers a saving in cost.

The consumer should purchase either $q_{i, t}^{*}$ as calculated or a smaller quantity than $q_{i, t}^{*}$ to last him or her until an expected deal, and plan to purchase again on this deal. Note that for the units that would be consumed after $T_{e, t}^{k_{\text {(exp) }}}$, the consumer can avoid these holding costs by buying on the expected deal at $T_{e, t}^{k_{\text {(exp) }}}$. We use $e$ to denote the brand that is expected to be on deal and emphasize that the expected deal could be on a different brand from the one on deal today (denoted by $i$ ). It also could be on the same brand (i.e., $e$ could equal $i$ ). Therefore, for all deals that occur before $T_{t}^{*}$, the consumer should com- 
pare DealSavings at time $t\left(=R-S_{i, t}-S C_{i}\right)$ less the holding cost per unit from time $t$ till the expected deal ( $=h T_{e, t}^{k_{\text {(exp) }}}$ ) against the DealSavings on the expected deal $\left(=R-S_{e, t}^{k_{\text {(exp) }}}-S C_{\mathrm{e}}\right)$. He or she should purchase only enough to last until $T_{e, t}^{k_{(\exp )}}$ if

$$
\begin{aligned}
& \text { Expected DealSavings } \geq \text { current DealSavings } \\
& \text { - holding cost per unit until the expected deal, }
\end{aligned}
$$

that is,

$$
R-S_{e, t}^{k_{(e x p)}}-S C_{e} \geq R-S_{i, t}-S C_{i}-h T_{i, t}^{k_{\text {(exp) }}}
$$

When the two sides of the equation are equal, the consumer is indifferent about whether he or she buys a large quantity on the deal now or buys less now and buys again on the expected deal. Therefore,

$$
\begin{aligned}
q_{i, t}^{* *}= & \min \left\{c T_{e, t}^{k_{\text {(exp) }}}-I_{t}\right\} \\
& \text { for all expected deals that } \\
& \text { satisfy equations } 4 \text { and } 5 \\
q_{i, t}^{* *}= & q_{i, t}^{*} \\
& \text { if no expected deal satisfies } \\
& \text { equations } 4 \text { and } 5 .
\end{aligned}
$$

$c T_{e, t}^{k_{\text {exp) }}}-I_{\mathrm{t}}$ is the amount that must be purchased to cover consumption needs exactly from now until the $k^{\text {th }}$ expected deal on brand $e . q_{i, t}^{*}$ is the amount that would be purchased in the absence of deals. If two expected deals satisfy equations 4 and 5 , the consumer will purchase to last until the earlier deal.

It should be noted that the consumer need not purchase to last until the first expected deal, but could purchase to last until a later expected deal. This could happen because the first expected deal might be on a less preferred brand that does not offer any savings over the deal today even with the holding cost until this deal added on (i.e., it does not satisfy equation 5). The same could happen if the first expected deal was on the preferred brand, but the price discount was very low on this deal.

\section{IMPLICATIONS OF THE MODEL}

The model permits one to compare the normative purchase behavior of consumers with and without knowledge of future deals. Implications are derived analytically in a comparative statics framework, that is, by varying the values of certain model parameters and studying the resultant effects on specific dependent variables. For simplicity of description and without loss of generality, we consider two brands, $i$ and $j$, which offer deals alternately. For the same reason, for aware consumers, we only consider the next expected deal. Let $n$ denote the current period in which a deal for brand $i$ occurs, $x$ denote the actual time to the next deal on brand $j$, and $y$ denote the actual time from the previous deal on brand $j$. Deal timing pattern refers to both the time between deals and the sequence of deals on different brands or deals with different price discount levels. ${ }^{3}$

The implications focus on purchase quantity and response to deals and costs and are as follows.

\section{Quantity}

$\mathbf{I}_{1}$ : Relative quantity purchased by aware consumers versus unaware consumers on any deal should depend on the deal timing pattern.

Here we assume that all other variables including deal frequency are held constant. Unawares could buy larger or smaller quantities than awares on any deal. The amount purchased on any specific deal will depend on the deal timing pattern. If deals occur close together, aware consumers should buy enough to last until the next deal $(=c x)$. Unaware consumers should purchase up to the maximum amount that they can while taking account of their current inventory (i.e., they should purchase up to $Q_{i, n}$ ). Their current inventory is equal to the amount of inventory after the last deal purchase less the amount of inventory used up since then. If the last deal was on brand $j$ and occurred $y$ periods back, then their current inventory is $Q_{j, n-y}-c y$. Hence, they should buy $Q_{i, n}-\left[Q_{j, n-y}\right.$ - cy] on deal today. The deal timing pattern affects the time interval since the last deal, hence the unaware consumer's current inventory at hand, and consequently how much he or she should buy now. Therefore, the quantity purchased by unaware consumers also is determined by the time between deals.

Because $Q_{(.), t}$ depends on $R, S_{(.), t}, S C_{(.)}, c, h$, which are all fixed, the amount purchased by unaware versus aware consumers will depend on the relative size of $c x$ and $c y$, and hence on the relative size of $x$ and $y$ (the times between deals). It also will depend on whether the deal on brand $i$ or $j$ occurred last, because this determines if awares are purchasing $c x$ or $c y$, and if unawares are purchasing $Q_{i, n}-\left[Q_{j, n-y}-c y\right]$ or $Q_{j, n}-\left[Q_{i, n-y}-\right.$ $c x]$.

The effect of deal timing pattern is illustrated in Table 1 , in which the timing of deals is different between deal timing patterns 1 and 2 . We can see in deal timing pattern 1 (equally spaced deals) that unaware consumers buy more of the preferred brand than the aware consumers (5 versus 3 ) and less of the less preferred brand ( 1 versus 3 ). In deal timing pattern 2 (adjacent deals) the relative quantity purchased by awares versus unawares is reversed totally. Unaware consumers buy less of the preferred brand than the aware consumers ( 3 versus 5$)$ and more of the less preferred brand ( 3 versus 1$)$. Hence, unaware consumers can buy less or more than aware consumers on any deal, depending on the deal timing pattern.

\footnotetext{
${ }^{3}$ If $R-S_{i, r}$ is the unaware consumer's perceived deal amount and not the actual deal amount, then we must assume that the perceived amount is greater than actual $R-S_{i, t}$ for the implications to follow through.
} 
Table 1

DEAL TIMING PATTERNS AND NORMATIVE PREDICTIONS FROM THE MODEL ${ }^{a, b, c}$

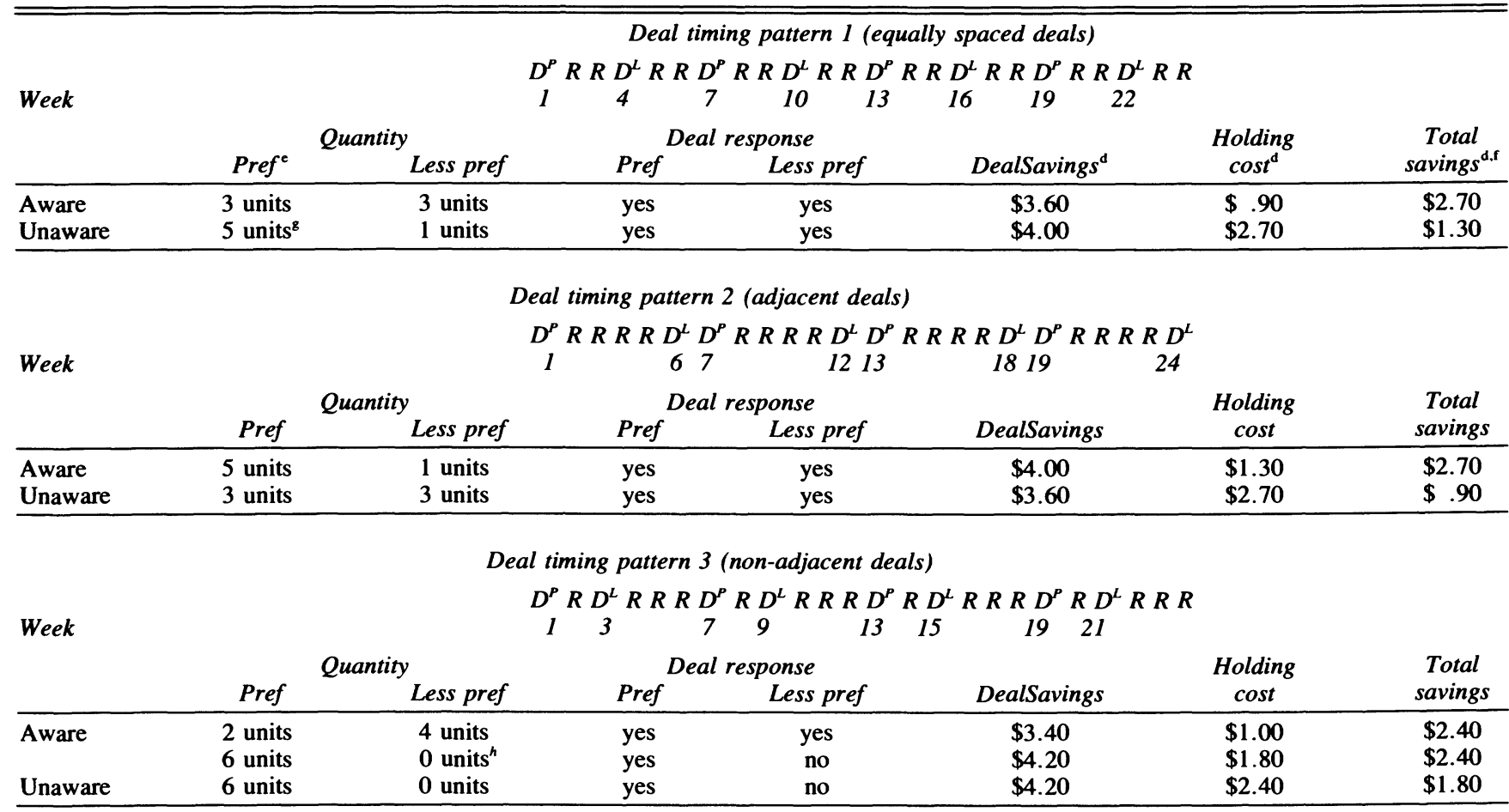

${ }^{2}$ DealSavings(preferred brand) $=\$ .70 ;$ DealSavings(less preferred brand) $=\$ .50 ; \mathrm{c}=1$ unit per week; $\mathrm{h}=\$ .10$ per unit per week;

${ }^{b} D^{P}$ denotes a deal on the preferred brand; $R$ denotes that there was no deal on either brand; $D^{L}$ denotes a deal on the less preferred brand

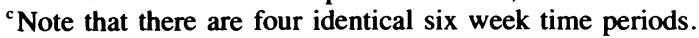

${ }^{\mathrm{d}}$ This is the cost/savings for a six-week time period.

'Pref denotes preferred.

f Total Savings = DealSavings - holding cost.

${ }^{8}$ This result holds after the purchasing pattern stabilizes, which happens from time period 2 , or week 7 . In the first time period the unaware consumer will buy seven units on this deal, but from the next time period he or she will purchase five units because he or she already will have two units in stock.

${ }^{\mathrm{h}} \mathrm{Aware}$ consumers will be indifferent between the behavior in the two rows.

$\mathbf{I}_{2}$ : (a) When deals occur infrequently enough that the inventory of unaware consumers has been used up by the time of the next deal, then there should be no difference between aware and unaware consumers in the quantity purchased on deal. However, (b) if deals occur frequently enough that the inventory of unaware consumers has not been used up, then there may be a difference between aware and unaware consumers in the quantity purchased on deal.

(2a) When deals occur infrequently enough that the inventory of unawares has been used up by the time of the next deal (time to the next deal, $x \geq Q_{i, n} / c$ ), then both awares and unawares purchase the same quantity on deal $\left(=Q_{i, n}\right)$. Basically, if the next deal is far into the future, the option for the aware consumers of buying less than the "myopic" optimum (i.e., optimum, not considering future deals) to last until the next deal goes away, because the amount necessary to last until the next deal is larger than the myopic optimum.

(2b) When deals occur frequently enough that the in- ventory of unaware consumers has not been used up $\left(x<Q_{i, n} / c\right)$, aware consumers purchase smaller quantities on deal to last until an expected deal $(=x c)$. Unaware consumers, on seeing a deal, purchase up to $Q_{i, n}$. If the previous deal was on brand $j$ and occurred $y$ periods back, they have inventory $\left(Q_{j, n-y}-y c\right)$ today. Hence, they can only purchase $Q_{i, n}-\left(Q_{j, n-y}-y c\right)$ on this deal. Consequently, if $Q_{j} \neq Q_{i}$ or $x \neq y$, then aware and unaware consumers may purchase different quantities on deal. $Q_{j, n-y} \neq Q_{i, n}$ implies that $R_{i}-S_{j, n-y}-S C_{j}$ $\neq R_{i}-S_{i, n}-S C_{i}$ (because $Q_{i, t}=R_{i}-S_{i, t}-S C_{i}(c / h)$ and $c, h$ are constant across deals). Therefore, if $R_{i}-$ $S_{i, n}-S C_{i}$ is different across deals, then aware and unaware consumers may purchase different quantities on deal. As can be seen, this could result from different deal amounts $\left(R_{i}-S_{i, n}\right)$ for the same brand, or because the deals in periods $n-y$ and $n$ are on different brands ( $S C_{i}$ is different, or $R_{i}-S_{i, n}$ is different for the two brands, or both).

This implication is illustrated in deal pattern 1 (equally 
spaced deals) of Table 1 . In this case, the aware consumer should purchase 3 units each on the deals for the preferred and the less preferred brands. However, the unaware consumer should purchase 5 units on the deal for the preferred brand and 1 unit on the deal for the less preferred brand.

\section{Response to Deals}

A consumer responds to a deal when he makes a purchase on that deal (i.e., buys any amount greater than zero on that deal). A larger response to a deal means that a larger number of consumers are purchasing on this deal.

$\mathbf{I}_{3}$ : (a) Irrespective of their current inventory, both aware and unaware consumers should purchase on all deals with the highest DealSavings. However, (b) aware consumers should be more likely to purchase on deals with less than the highest DealSavings versus unaware consumers.

(3a) Aware consumers can buy enough on a deal for brand $i$ today to last until the next expected deal on brand $j$. They then can purchase on this expected deal. They should do this if the expected deal offers some savings over purchasing now and carrying stock until this expected deal. As shown in equation 5, this occurs when

$$
\text { DealSavings }_{j, n+x} \geq \text { DealSavings }_{i, n}-h x .
$$

DealSavings $_{i, n}$ is the per-unit savings in purchase cost on the deal for brand $i$ today. $h x$ is the holding cost per unit of good from now (week $n$ ) until the next expected deal (which is expected in week $n+x$, i.e., after $x$ weeks). DealSavings $_{j, n+x}$ is the expected per-unit savings in purchase cost on the expected deal on brand $j$ in period $n+x$.

For an expected deal with the largest DealSavings, this condition will always hold, because DealSavings $s_{j, n+x}$ will be greater than or equal to DealSavings $s_{i, n}$ for that deal. Hence, aware consumers should purchase on all the deals with the largest DealSavings.

Unaware consumers should purchase on a future deal if their inventory at the time of the future deal is not greater than the optimal purchase quantity. Their inventory on a future deal is a function of their past myopic behavior. It is determined by the inventory after purchase today less how much they consume up to the future deal. On the deal today (i.e., period $n$ ) on brand $i$, these consumers purchase up to $Q_{i, n}$. They consume $x c$ units between now and $x$ periods from now (i.e., till period $n+x$ ). Therefore, their inventory in period $n+x$ $=Q_{i, n}-x c$. Hence, they should purchase on the future deal if $Q_{j, n+x}-\left[Q_{i, n}-c x\right]>0$.

For a future deal with the largest DealSavings, this condition will always hold. $Q_{(.)}=$DealSavings $_{(.)} c / h$. Hence, $Q($.$) will be the largest when DealSavings are$ the largest. Therefore, $Q_{j, n+x}$ will be $>Q_{i, n}$. Therefore, unaware consumers should never have enough inventory to prevent them from purchasing on the highest value deal. This shows that both aware and unaware con- sumers should purchase on all high-discount deals on the preferred brand.

(3b) Aware consumers should purchase on the next expected deal if

$$
\text { DealSavings }_{j, n+x}>\text { DealSavings }_{i, n}-h x
$$

and should be indifferent between purchasing and not purchasing if the two sides are equal. Unaware consumers should purchase on this future deal only if

$$
\begin{gathered}
Q_{j, n+x}-\left[Q_{i, x}-c x\right]>0 \\
\Rightarrow \text { DealSavings }_{j, n+x}>\text { DealSavings }_{i, n}-h x, \\
\text { since } Q_{(.)}=\text {DealSavings }_{(.)} c / h
\end{gathered}
$$

Hence, the condition for purchasing on deals for unawares is the same as that for awares, except that awares could purchase on the deal even when

$$
\text { DealSavings }_{j, n+x}=\text { DealSavings }_{i, n}-h x,
$$

whereas unawares should not.

Basically, awares do not buy huge quantities of their preferred brand on deal, so they can take advantage of intervening deals on their second preferred brand. In contrast, unawares buy huge quantities of their preferred brand on deal. Hence, if a certain deal occurs soon after a very good deal, then unaware consumers either buy nothing on this deal or buy very little on it.

Let us assume for simplicity that both brands have two discount levels (high and low), which are equal for the two brands. Multiple discount levels could in fact be true for many brands. For example, Raju (1990) found that a six-pack of Dr. Pepper is on deal for either $\$ 1.99$ or $\$ 1.69$. In this case the highest DealSavings are for the preferred brand when it offers the high discount. DealSavings on the other deals are lower because of lower discount levels or lower brand preference or both. Here, both awares and unawares should purchase on all high discount deals for the less preferred brand. However, the awares should be more likely to purchase on all the other deals. This suggests the following:

- Aware consumers could be more likely to purchase on deals on less preferred brands compared with unaware consumers,

- Aware consumers could be more likely to purchase on low-value deals on the preferred brand compared with unaware consumers, and

- If the preferred brand has multiple discounts, then the aware consumers could be more likely to purchase on deals for the preferred brand overall compared with the unaware consumers.

$\mathbf{I}_{4}$ : If the awares skip a deal, so should the unaware (but not vice versa). The aware consumer should skip a future deal if

$$
\text { DealSavings }_{j, n+x}<\text { DealSavings }_{i, n}-h x
$$

and also could skip the future deal if the left-hand side was equal to the right-hand side in the inequality. The unaware should skip a future deal if 


$$
\text { DealSavings }_{j, n+x} \leq \text { DealSavings }_{i, n}-h x
$$

as shown under $\mathbf{I}_{3 \mathrm{~b}}$. Hence, the unaware should always skip a deal when the awares do.

One may think that the aware consumer might skip a low value deal if he or she knows that a high-value deal is coming soon, whereas the unaware consumer would stock up on this deal. However, one must remember that awares can reduce purchasing on the prior deal in anticipation of the low-value deal if the savings in holding cost (by purchasing only until the low-value deal, and then purchasing on the low-value deal) outweigh the loss in Dealsavings associated with the low-value deal. Therefore, awares can purchase on deal today to last until the low-value deal, and then purchase a small quantity on the low-value deal to last until the high-value deal.

I5: Response to specific deals should be determined by the deal timing pattern, not the relative frequency of different types of deals (different brands or discount levels).

As seen in the analysis for $\mathbf{I}_{4}$, response to deals for two brands, $i$ and $j$, by both aware and unaware consumers, is determined by the relationship between DealSavings $_{i, n}$, DealSavings $s_{j, n+x}$ and the time between the two deals, $x$. If DealSavings $i_{i,(.)}$ and DealSavings ${ }_{j,(.)}$ are fixed, it is basically determined by $x$. The smaller $x$ is, the less likely is a consumer to purchase on the next deal. $x$ could have nothing to do with the frequency of deals, ${ }^{4}$ but depends on the deal timing pattern. Therefore, deal frequency in and of itself does not affect relative purchase behavior of aware and unaware consumers but only affects it through its impact on the time between deals.

This is illustrated by deal timing patterns 2 and 3 in Table 1. In deal pattern 2 (adjacent deals), the deal on the less preferred brand occurs in the period before (or five periods after) the deal on the preferred brand. In deal pattern 3 , the deal on the less preferred brand occurs four periods before (or two periods after) the deal on the preferred brand.

One can see that in deal timing pattern 2 (adjacent deals) both aware and unaware consumers should purchase on deals for the less preferred brand. In deal timing pattern 3 (nonadjacent deals), the unaware consumers should not purchase on the deal on the less preferred brand. However, the aware consumers could purchase on deals on the less preferred brand. Hence, if a deal for the less preferred brand occurs soon after a deal for the preferred brand, unaware consumers may not purchase on this deal, whereas aware consumers may purchase on the deal. However, if a deal for the less preferred brand occurs a long time after a deal for the

\footnotetext{
${ }^{4}$ Time between deals is affected by deal frequency to the extent that the largest time between deals is determined by deal frequency. For example, if deal frequency is twice a month, then the largest time between deals cannot exceed a month.
}

preferred brand, both unaware and aware consumers may purchase on the deal.

Costs

I $_{6}$ : Unaware consumers could have lower purchasing costs (or higher DealSavings) than aware consumers. The relative purchasing costs of unaware versus aware consumers will depend on the deal timing pattern.

The unaware consumer may buy so much on a deal for the more preferred brand that he or she purchases very little or nothing at all on the next deal, which may be on the less preferred brand. However, the aware consumer may purchase only enough on the deal for the preferred brand to last him or her until the next deal on the less preferred brand, and hence purchase a substantial quantity on the deal for the less preferred brand. This could lead to higher purchasing costs for the aware consumer. The relative purchasing costs of aware and unaware consumers should depend on the deal timing pattern.

This can be seen in the three dealing patterns in Table 1. In dealing pattern 2 (adjacent deals), unaware consumers have higher purchasing costs (lower DealSavings) compared with unaware consumers. However, in dealing patterns 1 (equally spaced deals) and 3 (nonadjacent deals), aware consumers have lower DealSavings compared to unaware consumers.

I7: Unaware consumers will have a weakly ${ }^{5}$ higher average inventory compared with aware consumers, and hence weakly higher holding costs.

Aware consumers will exhaust their inventory by the time the next deal occurs, whereas unaware consumers may not. This will lead unaware consumers to have a higher inventory, and hence higher holding costs compared with aware consumers. This can be seen in the three dealing patterns in Table 1.

I : Unaware consumers will have weakly higher total costs (purchase costs plus holding costs) compared with aware consumers.

Unaware consumers will have higher holding costs compared with aware consumers. They could have lower purchasing costs. However, the aware consumers will incur higher purchasing costs only if the savings in holding costs compensate for the loss in purchasing costs. Hence, the aware will have the same or lower total costs (=same or higher total savings, where total savings equal DealSavings - holding cost) compared with the unaware consumers. This can be seen in Table 1 in dealing patterns 1 and 3. Unaware consumers have lower purchasing costs compared with aware consumers. However, they have much higher holding costs and hence higher total costs.

\footnotetext{
${ }^{5}$ By weakly higher we mean $\geq$ as opposed to strictly higher, which means $>$.
} 


\section{Overview of Implications}

Overall, the model implies that if deals occur infrequently the behavior of awares and unawares is similar. Therefore, if there is infrequent dealing in the market, it may not pay a consumer to learn about future deals, because there could be little difference in purchase behavior between unaware and aware consumers.

If deals occur frequently, the behavior of awares and unawares is different. Both should purchase on all highdiscount deals on the preferred brand. Unawares should be less likely to purchase on low-discount deals and on deals on the less preferred brands. This lack of response will depend on the deal timing pattern. The relative purchase quantity of awares versus unawares also will depend on the deal timing pattern. Unaware consumers could have a lower purchasing cost (higher DealSavings) compared with aware consumers depending on the deal timing pattern. However, unaware consumers will have a higher holding cost, so that their total cost will be higher than that for the aware consumers.

\section{EMPIRICAL SUPPORT FOR THE MODEL IMPLICATIONS}

We tested some of the model implications in an interactive computer-simulated shopping experiment using personal computers. ${ }^{6}$ Computer-simulated shopping experiments also have been used by other researchers (Buyyukurt 1986; Kahn and Raju 1989; Meyer and Assuncao 1990; Simonson and Winer 1990).

The experiment attempts to get a clean, internally valid test of how these forces might work in the real world. If we were to investigate these issues by observational, correlational methods, we would not find enough variance in the independent variables without having confounding variance in other factors as well. For example, deal knowledge is likely to be confounded with subjective variance among brands in substitution costs, and deal frequency is likely to be confounded with deal timing pattern.

\section{Experiment Design}

Overview. 64 graduate business students participated in the experiment as a requirement for certain marketing classes. ${ }^{7}$ They were randomly assigned to experiment conditions. The experiment was done only under the high deal frequency scenario, because deal knowledge is less relevant when there are few deals. We used two brands, preferred and less preferred. Deals for each of the two brands occurred four times in 24 weeks (once every six weeks).

Experiment design and manipulations. A $2 \times 2$ (be-

\footnotetext{
${ }^{6} \mathrm{We}$ did not test $\mathbf{I}_{2 \mathrm{a}}$ and $\mathbf{I}_{4}$ because this would necessitate quadrupling the number of treatments.

${ }^{7}$ The results for one subject were not used. This subject displayed a desire to purchase 100 bottles of soda on the first purchase occasion.
}

tween subjects: deal knowledge $\times$ deal timing pattern) $\times$ 3(within subject: time period) design was used with 16 subjects in each between-subjects cell. In the aware condition of deal knowledge, subjects were told when deals on both brands would occur and what the deal price would be. In the unaware condition, subjects were not told anything about when deals occurred. In deal timing pattern 1 (equally spaced deals), deals occurred every three weeks (alternating between the preferred and less preferred brands). In deal timing pattern 2 (adjacent deals), the deal on the less preferred brand occurred the week prior to the deal on the preferred brand. Deal patterns are given in Table 2 .

To control for order effects, one-half the subjects in each treatment were exposed to a deal on the less preferred brand first and one-half to the preferred brand first. However, order effects were not found to be significant. ${ }^{8}$

Control for learning effects. We expected that as unaware consumers learned about deals, their behavior would become closer to that of aware consumers. Therefore, there would be less difference in behavior the further along in the experiment that the subjects went. To control for learning of expectations among unaware consumers, we divided the 24-week experiment period into four six-week periods (in each of which there was one deal for the preferred brand and one for the less preferred brand). We then treated "time period" as a repeated factor. Because consumers started with zero inventory and it takes some time for inventory effects to build up, we treat the first time period as a stabilization period. A stabilization period is also important because we are switching the order of deals (less preferred first or more preferred first) to control for order effects. Hence, only the results of time periods 2 to 4 are analyzed.

Dependent variables. The dependent variables are average deal purchase quantity and likelihood of deal response for the preferred and less preferred brands, and the holding cost, savings in purchase cost, and total savings.

\section{Procedure}

The experiment took subjects between ten and 25 minutes. Subjects worked individually. They were told that they were in a foreign country where price patterns are very different from those in the United States. They were asked to make successive purchase decisions over 24

\footnotetext{
${ }^{8}$ Order effects were not significant for average quantity purchased on deal of either brand, response to deals on the less preferred brand, holding cost, purchase cost, or total cost $(p>.1)$. Also, chi-square tests showed that $\log$ likelihood of deal response was not significantly different for a model with order effects and a model without order effects $(p>.1)$. One should note that order effects are obviously significant for the stabilization time period because inventory effects are required to negate order effects, and a stabilization period is needed to build up inventory effects.
} 
Table 2

DEAL TIMING PATTERNS AND NORMATIVE PREDICTIONS FOR THE EXPERIMENT ${ }^{\mathrm{a}, \mathrm{b}, \mathrm{c}, \mathrm{d}}$

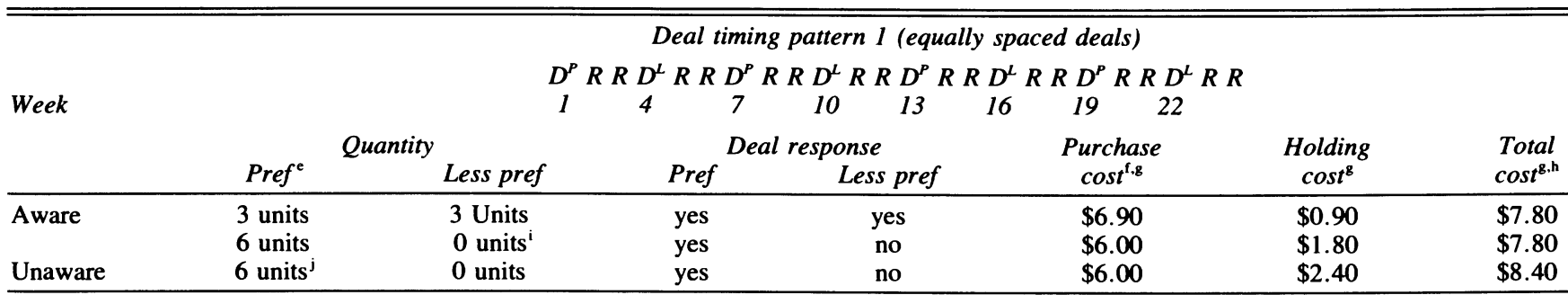

Deal timing pattern 2 (adjacent deals)

\begin{tabular}{|c|c|c|c|c|c|c|c|}
\hline \multirow{4}{*}{ Week } & \multicolumn{7}{|c|}{$D^{P} R R R R D^{L} D^{P} R R R R D^{L} D^{P} R R R R D^{L} D^{P} R R R R D^{L}$} \\
\hline & & & 6 & 1213 & 819 & & \\
\hline & \multicolumn{2}{|c|}{ Quantity } & \multicolumn{2}{|c|}{ Deal response } & \multirow{2}{*}{$\begin{array}{c}\text { Purchase } \\
\text { cost }\end{array}$} & \multirow{2}{*}{$\begin{array}{c}\text { Holding } \\
\text { cost }\end{array}$} & \multirow{2}{*}{$\begin{array}{c}\text { Total } \\
\text { cost }\end{array}$} \\
\hline & Pref $^{e}$ & Less pref & Pref & Less pref & & & \\
\hline Aware & 5 units & 1 units & yes & yes & $\$ 6.30$ & $\$ 1.30$ & $\$ 7.60$ \\
\hline Unaware & 4 units & 2 units & yes & yes & $\$ 6.60$ & $\$ 2.60$ & $\$ 9.20$ \\
\hline
\end{tabular}

${ }^{a}$ DealSaving $s_{\text {pref }}=\$ .70 ;$ DealSavings $s_{\text {less pref }}=\$ .40 ; \mathrm{c}=1$ unit per week; $\mathrm{h}=\$ .10$ per unit per week; Regular price of both brands $=\$ 1.70$.

${ }^{\mathrm{b}} \mathrm{D}^{\mathrm{P}}$ denotes a deal on the preferred brand; $\mathrm{R}$ denotes that there was no deal on either brand; $\mathrm{D}^{\mathrm{L}}$ denotes a deal on the less preferred brand.

'Note that there are four identical six-week time periods.

${ }^{\mathrm{d}}$ To control for order effects, some subjects saw the deal on the preferred brand first, and some saw the deal on the less preferred brand first.

Hence, in deal timing pattern 1, the deal pattern was as if it began from week 4 , and in deal timing pattern 2 as if it began from week 6.

${ }^{\mathrm{e}}$ Pref denotes preferred.

${ }^{f}$ This is the cost of purchasing adjusted for brand preference.

${ }^{8}$ This is the cost for a six-week time period.

${ }^{\text {h }}$ Total cost $=$ Purchase cost + holding cost.

'Aware consumers will be indifferent between the behavior in the two rows.

${ }^{j}$ This result holds after the purchasing pattern stabilizes which happens from time period 2 , or week 7 . In the first time period the unaware consumer will buy seven units on this deal, but from the next time period he will purchase six units because he will already have one unit in stock.

simulated weeks between two brands of soft drinks. ${ }^{9}$ Each subject selected his or her two most preferred brands of soft drink. His or her substitution cost for the less preferred brand was deduced by the price-until-switching approach (the difference in price between the preferred and a less preferred brand before the subject buys the less preferred brand; Jacoby and Chestnut 1978). ${ }^{10}$ Testretest reliability of this measure is high $(r=0.82$; Olson and Jacoby 1971), and results are found to be similar whether one measures substitution cost by either reducing or increasing the target brand relative to the competition (Jacoby and Kyner 1973). The deal price for the preferred brand was $\$ .70$ less than the regular price for the brand ( $\$ 1.70$ and $\$ 1.00$ for two liter bottles). The deal price of the less preferred brand was linked to the substitution cost indicated by each subject so that the savings in cost adjusted for preferences (= DealSavings

\footnotetext{
${ }^{9}$ To avoid any end-game effects on purchases and inventory, subjects were not told the number of weeks for which they had to shop.

${ }^{10} \mathrm{We}$ did not give the subjects two hypothetical brands and then tell them their substitution cost for the named less preferred brand, because this would have been less realistic.
}

$\left.=R-S_{i}-S C_{i, t}\right)$ for the less preferred brand was $\$ .40$. Hence, the deal price of the less preferred brand was interactively determined for each subject and was $\$ 1.70$ $-.40-$ Substitution Cost (indicated by each subject). ${ }^{11}$

The experiment is designed to be consistent with the assumptions of the model. Hence, subjects were told that they consumed a two-liter bottle of soda per week and that they incurred a cost of $\$ .10$ per bottle per week for storing the bottle. They went to the store each week, so that they had no extra cost of purchasing soda. Their objective was to minimize the cost of purchasing and storing soda.

A manipulation check determining consumer deal knowledge following the experiment revealed that subjects in the unaware condition learned something about market conditions by the end of the experiment. Subjects knew that deals occurred often, but there was a variance in knowledge about how often they occurred. Guesses across subjects ranged between once every two to eight

\footnotetext{
"If we had kept the same deal price for the preferred and less preferred brands, it is possible that subjects with substitution costs greater than $\$ .40$ never considered purchasing the less preferred brand.
} 
weeks for the preferred brand (mean $=5.44$ weeks; variance $=1.62$ weeks), and between two and nine weeks (mean $=5.66$ weeks; variance $=2.72$ weeks) for the less preferred brand. As expected, aware consumers knew the correct time between deals for both brands.

\section{Results}

We describe the results in the same order that we developed the implications. Because of the way we designed the experiment, we expect large differences in behavior between aware and unaware consumers in deal timing pattern 1 (equally spaced deals) but not in deal timing pattern 2 (adjacent deals) (see normative values for dependent variables in Table 2). This also implies that we do not expect unaware consumers to display much learning in deal timing pattern 2 . To elaborate, as the unaware become more aware, one should expect their behavior to become closer to that of the aware. In deal timing pattern 1 (equally spaced deals), the margin for this change is there, and hence one can observe the "learning." However, in deal timing pattern 2 (adjacent deals), the normative behavior of awares and unawares is very similar, and hence, even though the unawares may learn the deal timing pattern, their behavior will not change much and we will not observe the "learning" effect. The values of the seven dependent variables for the different treatments in each of the three relevant time periods are given in Table 3 .

Average quantity purchased on deal. Empirical tests of implications for deal purchase quantity were done using a series of repeated-measures ANOVA. We report the results of multivariate tests.

$I_{1}$ states that the relative quantity purchased by awares versus unawares on any deal should depend on the deal timing pattern. As stated previously, we expect large differences in average quantity purchased on deal between aware and unaware consumers in deal timing pattern 1 (equally spaced deals) but not in deal timing pattern 2 (adjacent deals). We analyzed the results separately for each brand.

Preferred brand. Repeated-measures ANOVA for average deal purchase quantity of the more preferred brand reveals significant effects for deal knowledge $(F(1,60)$ $=4.3, p<.05)$, deal timing pattern $(\mathrm{F}(1,60)=11.49$, $p<.01)$, and their interaction $(\mathrm{F}(1,60)=19.38, p<$ $.001)$. Simple main effects tests reveal that unaware consumers purchased significantly larger quantities of the preferred brand on deal compared with aware consumers in deal timing pattern $1(\overline{\mathrm{X}}=4.67$ versus $\overline{\mathrm{X}}=3.33$; $\mathrm{F}(1,60)=20.97, p<.001) .{ }^{12}$ However, they purchased mildly significantly smaller quantities than aware consumers in deal timing pattern $2(\bar{X}=4.46$ vs. 4.94; $\mathrm{F}(1,60)=2.71, p<.1)$. As expected (see normative

\footnotetext{
${ }^{12}$ One-tailed tests are used whenever relative statements (bigger, smaller) are made. Two-tailed tests are used whenever equality statements (no difference) are made.
}

values in Table 1), quantity purchased by awares versus unawares on any deal depends on the deal timing pattern. $\mathbf{I}_{1}$ is supported.

In addition, we find significant effects for all interactions involving time period, namely, deal knowledge and time-period $(\mathrm{F}(2,59)=3.81, p<.05)$, time-period and deal timing pattern $(\mathrm{F}(2,59)=8.30, p<.01)$, and time period, deal knowledge, and deal timing pattern $(\mathrm{F}(2,59)=9.07, p<.001){ }^{13}$ Follow-up contrasts exhibited "learning" of the dealing pattern by the unaware consumers. Thus, aware and unaware consumers purchase significantly different quantities on deal in earlier time periods compared with later ones. In time period 2, unaware consumers purchase significantly larger quantities compared with aware consumers in deal timing pattern $1(p<.01)$, and significantly smaller quantities in deal timing pattern $2(p<.01)$. In time period 3 , unaware consumers purchase significantly larger quantities compared with unaware consumers in deal timing pattern $1(p<.01)$, but there was no significant difference in deal timing pattern $2(p>.2)$. In time period 4 , unaware consumers purchased marginally significantly larger quantities than aware consumers in deal timing pattern $1(p<.1)$, but there was no significant difference in deal timing pattern $2(p>.2)$. Hence, as unaware consumers learn the deal pattern and become more aware, their behavior is closer to that of aware consumers.

Less preferred brand. Very similar results were obtained for average deal purchase quantity of the less preferred brand. Aware consumers purchased significantly larger quantities of the less preferred brand on deal compared with unaware consumers in deal timing pattern 1 $(\overline{\mathrm{X}}=2.67$ vs. $\overline{\mathrm{X}}=1.31 ; \mathrm{F}(1,60)=15.49, p<.001)$. They purchased smaller quantities than unaware consumers in deal timing pattern 2 but the difference was not significant $(\overline{\mathrm{X}}=1.35$ versus $1.56 ; \mathrm{F}(1,60)=.37$, $p>.5$ ). In deal pattern 1 (equally spaced deals), the deals on the less preferred brand occurred quite soon after deals for the preferred brand. Unaware consumers still had a lot of inventory left over from the previous deal, and thus did not purchase, or purchased very little on the deal for the less preferred brand. However, aware consumers could foresee this deal, and hence could plan to exhaust their inventory by that time and thus purchase on this deal. In deal timing pattern 2 (adjacent deals), deals on the less preferred brand occurred quite a while after deals on the preferred brand. By this time the unaware consumers had exhausted most of their inventory from the deal on the preferred brand. Hence, they could purchase substantial quantities on this deal. Therefore, the behavior of awares and unawares was quite similar.

"Learning" by unaware consumers also is observed in purchases for the less preferred brand. The difference in purchase behavior is significant in previous time pe-

\footnotetext{
${ }^{13}$ Results involving within-subject factors were identical for Pillais, Hotelling, Wilks, or Roys tests.
} 
Table 3

EXPERIMENT RESULTS

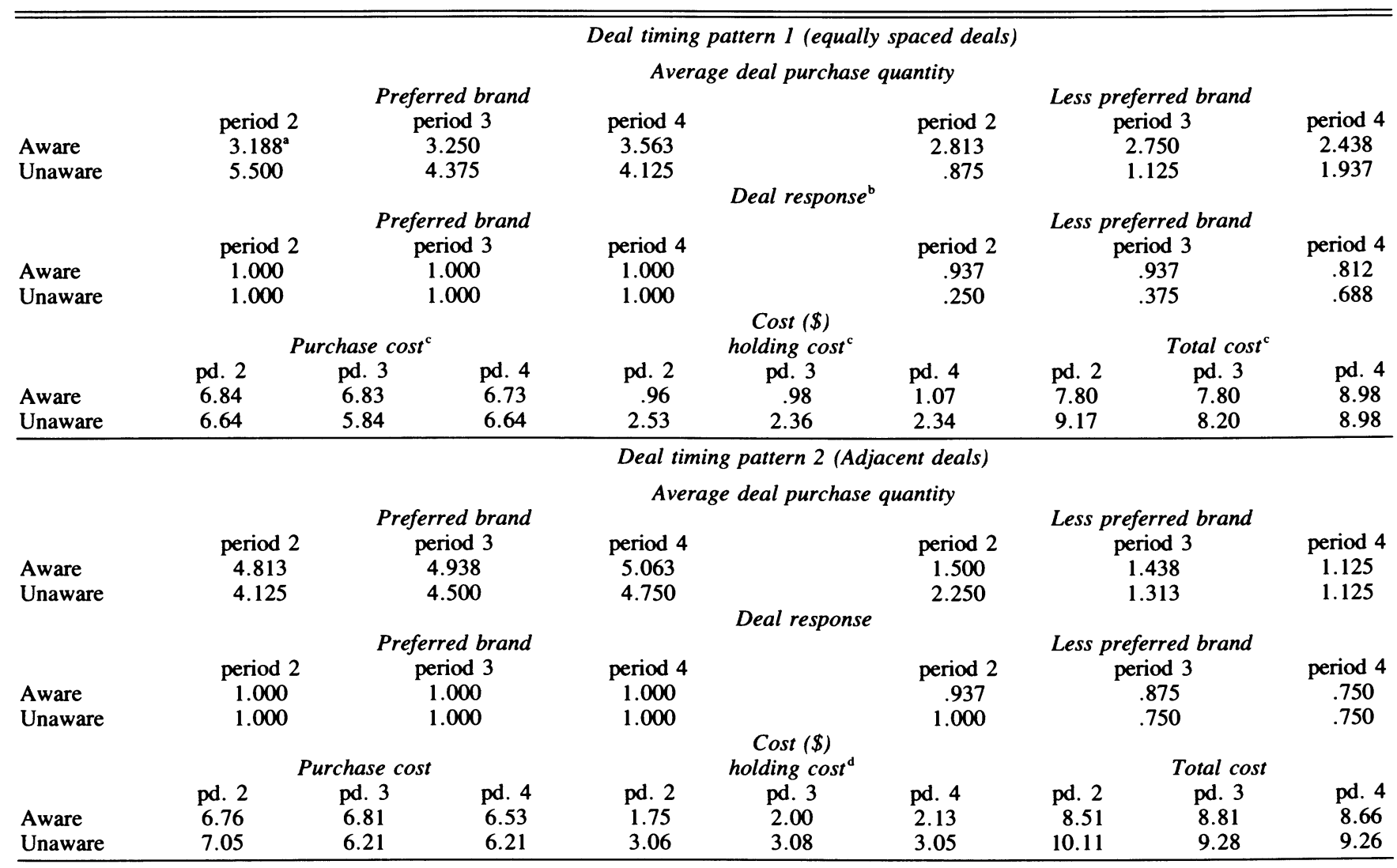

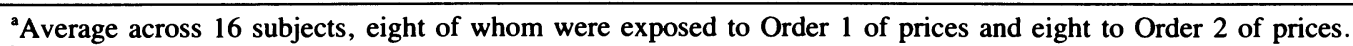

${ }^{b}$ Deal response is the percentage of deals on which a purchase was made averaged across subjects.

${ }^{\mathrm{C}}$ This is the cost for a six-week time period.

${ }^{\mathrm{d}}$ In deal timing pattern 2, both awares and unawares tended to carry larger inventories. These inventories were built up in time period 1 . One should also realize that increasing purchase quantity by 1 unit increases holding costs by a lot.

riods, but not in later ones [significant in deal timing pattern $1(p<.01)$ and mildly significant in deal timing pattern $2(p<.1)$ for time period 2; significant in deal timing pattern 1 in time period $3(p<.01)$; and not significant in either deal timing pattern in time period 4 $(p>.1)]$.

$\mathbf{I}_{2 b}$ states that if deals occur frequently enough that the inventory of unaware consumers has not been used up, then there could be a difference between aware and unaware consumers in the quantity purchased on deal. This implication is supported by the same analysis that was pertinent to $\mathbf{I}_{1}$.

Response to deals. $\mathbf{I}_{3 \mathrm{a}}$ suggests that both aware and unaware consumers should purchase on all the deals with the highest DealSavings. This implies that both aware and unaware consumers should purchase on all the deals on the preferred brand. This implication got very strong support. Every subject purchased on every deal for the preferred brand.

$\mathbf{I}_{3 \mathrm{~b}}$ suggests that aware consumers could be more likely to purchase on deals on less preferred brands compared with unaware consumers. We expect differences in response to deals for the less preferred brand in deal timing pattern 1 (equally spaced deals), but not in deal timing pattern 2 (adjacent deals).

Likelihood of response to deals on any brand in each period describes whether or not the subject purchased on the deal for that brand in that period. Because this variable only takes on values of 0 or 1 , we used a logit model to estimate deal response. ${ }^{14}$ The independent variables are all main effects and interactions for deal knowledge, deal timing pattern, and time period. We found significant main effects and two-level interactions for

\footnotetext{
${ }^{14}$ The deal response for unaware consumers in time period 2 and deal timing pattern 2 was 1.00 . We changed this to .9375 (i.e., 15 of the 16 subjects purchased on the deal) to run the log-linear model. Making this change does not affect the results, as can be seen by examining the deal response values in Table 1 .
} 
deal knowledge, deal timing pattern, and deal period $(p<.05)$.

As expected, the deal response of unawares was not significantly different from awares in deal timing pattern $2(p>.25)$. Here, deals for the less preferred brand occurred quite some time after deals for the preferred brand. In deal timing pattern 1 , the deal for the less preferred brand occurs soon after the deal for the preferred brand. Aware consumers were significantly more likely to purchase on a deal compared with unaware consumers in earlier time periods (periods 2 and $3, p<.01$ ), though not in later time periods when they had "learned" the deal timing pattern (period $4, p>.2$ ). $\mathbf{I}_{3 \mathrm{~b}}$ is supported.

$I_{5}$ states that the response to deals should be determined by deal timing pattern, not by the relative frequency. This implication is supported by the same analysis that was pertinent to $\mathbf{I}_{3 b}$.

$\mathbf{I}_{6}$ states that unaware consumers can have lower purchasing costs compared with aware consumers and that the relative purchasing costs of unaware versus aware consumers will depend on the deal timing pattern. We expect large differences in purchase costs between aware and unaware consumers in deal timing pattern 1 (equally spaced deals), but not in deal timing pattern 2 (adjacent deals). Total quantity purchased by awares and unawares in each time period was not the same. Hence, we tested difference in unit purchase cost between aware consumers and unaware consumers. Repeated-measures ANOVA for unit purchase cost brand reveals significant effects for deal knowledge $(\mathrm{F}(1,60)=6.57, p<.05)$, deal timing pattern $(\mathrm{F}(1,60)=6.66, p<.05)$, and for the interaction of deal knowledge and deal timing pattern $(\mathrm{F}(1,60)=20.26, p<.001)$. Simple main effects tests reveal that aware consumers had significantly larger purchase costs compared with unaware consumers in deal timing pattern $1(\mathrm{~F}(1,60)=21.14, p<.001)$, but the difference was not significant in deal timing pattern 2 $(p>.5)$. This is as we expected and confirms $\mathbf{I}_{6}$.

This occurred because in deal timing pattern 1 the unawares were purchasing much more on the preferred brand compared with the awares, who were purchasing on deals for both the preferred and less preferred brands. The awares therefore have higher unit purchasing costs. In deal timing pattern 2 , the awares and unawares purchase similar quantities on deal for both brands.

$\mathbf{I}_{7}$ stated that unaware consumers will have a weakly higher average holding costs compared with aware consumers. Repeated-measures ANOVA for holding cost reveals significant main effects for deal knowledge $(\mathrm{F}(1,60)=49.16, p<.001)$ and deal timing pattern $(\mathrm{F}(1,60)=20.14, p<.001)$, but not for the interaction $(p>.25)$. One can see from Table 3 that unaware consumers have consistently higher holding costs compared with unaware consumers. They were always holding a higher inventory than the aware consumers.

$\mathbf{I}_{8}$ stated that unaware consumers will have weakly higher total costs (purchase cost plus holding cost) than aware consumers. Repeated-measures ANOVA for total cost reveals significant main effects for deal knowledge $(\mathrm{F}(1,60)=9.58, p<.01)$ and deal timing pattern $(\mathrm{F}(1,60)$ $=7.16, p<.05)$, but not for the interaction $(p>.5)$. Table 3 shows that unaware consumers had consistently higher total costs compared with unaware consumers. Even though purchase cost is lower for unawares in deal timing pattern 1, their holding cost is much higher, so that their total cost is higher than that of the awares.

\section{Overview of Experiment Results}

In general, the laboratory study lends good support for the model implications. As in all tests of normative models, the actual behavior did not exactly match the predicted behavior. In deal timing pattern 1 , of 16 aware subjects, 13 purchased three units each on deals for both brands. The model had indicated that subjects would be indifferent between buying three units of each brand on deal and buying six units of the preferred brand on deal while passing up deals on the less preferred brand. In addition, the model predicted that both unaware and aware consumers would purchase on all deals on both brands in deal timing pattern 2. But in the experiment, aware consumers purchased on $85.4 \%$ of the deals on the less preferred brand and unawares purchased on $83.3 \%$ of the deals on the less preferred brand.

However, the model is useful in providing directional results most of which were supported in the experiment. The aware consumers especially behaved in a manner very close to what the model predicts. This could be because it was easy to determine optimal behavior in the aware case (just buy enough to last until the next deal). Unaware consumers displayed a lot of learning and there was less difference in the behavior of awares and unawares as the experiment progressed. One might wonder why consumers in the experiment learn about deals whereas consumers in the real world remain unaware. This has to do with the fact that 24 shopping occasions were condensed into 10-20 minutes in the experiment. In addition, in the experiment, consumers were being shown prices only for one product, whereas in the real world they would be exposed to enormous amount of information at once.

The experiment provides support for internal validity of the model. The external validity of the results depends on whether the experiment held constant background factors that vary in the real world and would interact with the experimental manipulations. These background factors might be consumer specific-for example, substitution cost, holding cost, consumption rate-or related to dealing patterns - for example, deal frequency, discount level, the sequence of deals, the time between deals.

One observation that lends some external support to the model implications is that many consumers in scanner data sets purchase almost exclusively on deal, whereas others do not. For example, in IRI coffee data in a 36week period, we found that $32.7 \%$ of the households purchased exclusively on deal, whereas $6.6 \%$ made less 
than $10 \%$ of their purchases on deal. This provides some evidence of consumer anticipation of deals. It indicates that some consumers have a rough idea of when to expect the next deal and thus purchase to last from deal to deal, whereas other consumers do not. However, it could also be the case that if deals occur frequently and if interdeal time does not vary a lot, then consumers without any anticipation of deals also can buy exclusively on deal by purchasing to bring their inventory up to large quantities.

\section{MANAGERIAL IMPLICATIONS}

Several managerial implications follow from the model and the experiment. The experiment demonstrates that if deals occur frequently, consumers will purchase from deal to deal whether or not they are aware of future deals. Aware consumers will have the foresight to be able to purchase only on deal, and unaware consumers will have too much current inventory to purchase off deal. Also, consumers will purchase small quantities on deal because consumption rate remains the same, and consumers do not want to perpetually build up their inventory. Therefore, in a frequently promoted product class, consumers will not purchase as large a quantity on deal as in an infrequently promoted product class, and retailers will not be able to pass on as much of their inventory holding costs to consumers (Blattberg, Eppen, and Lieberman 1981).

In addition, with high dealing in the market, consumers may not purchase on deals on less preferred brands (unless the discount is very high). Thus, new and less preferred brands could be forced to offer especially good deals to get consumers to purchase on them. The model also implies that in product classes with many consumer deals and low brand loyalty, one should expect some consumers to do a lot of brand switching but not buy large quantities on deal.

Another interesting result from the experiment is that response to deals on less preferred brands is not determined by the relative frequency of deals on preferred and less preferred brands, but on the deal timing pattern on these brands. The model suggests that if a deal on the less preferred brand occurs much after a deal on the preferred brand, rather than just after a deal on the preferred brand, then consumers would be more likely to purchase on the deal on the less preferred brand.

One might think that if deal frequency is high for good deals, aware consumers will not purchase on not-so-good deals because they can anticipate the better deals. But the unawares could purchase on not-so-good deals because they might think of deals as being rare. However, the model suggests that whenever the aware consumers skip a deal, the unawares also do so because of their high inventories after good deals.

The model indicates that if consumers have high holding costs, they will display more switching and less stockpiling compared with consumers with low holding costs. This could explain some of the counter-intuitive empirical results that have been found about the "dealprone consumer." These results show that, contrary to what one might expect based on the economic notion that low-income people should engage in more price search, low-income people are less sensitive to deals than are high-income people (Bawa and Shoemaker 1987; Blattberg et al. 1978). One reason could be that storage space is more precious for low-income people (because they live in smaller spaces). Hence, they may not be able to take advantage of deals because they already may have enough stock on hand so that they do not buy on deals.

\section{CONCLUSIONS}

Our main objective was to understand how deal knowledge can affect consumer purchase behavior. The model and resulting implications hold under the assumptions made. It is important to consider how relaxing the model assumptions will affect the model predictions. For example, the consumer's brand choice process may be much more complex than in our model. Consumer preferences could change over time because of variety seeking or other reasons. Substitution cost would then have to be modeled differently. For example, the substitution cost of a brand could be a function of the quantity of different brands purchased thus far.

Aware consumers may not have perfect information about deal prices and deal timing. If instead of knowing future deal prices exactly, aware consumers are uncertain about them, they should use the mean expected deal price in their purchase decision if they are risk neutral (i.e., a dollar savings is valued equal to a dollar loss). In this case, all that needs to be changed in the model is that expected DealSavings be replaced by expected mean DealSavings. All the model implications would still follow through, except for $\mathbf{I}_{4}$, which states that the unawares will skip a deal whenever the awares do. $\mathbf{I}_{4}$ would now be less extreme and state that the unawares will be more likely to skip a deal compared with the awares. Proofs are available from the author.

As far as deal timing is concerned, if consumers are certain about when a future deal will occur they should purchase up to the time when the deal is expected. However, if they are not sure about when a future deal will occur, the time until they should purchase will be determined by the trade-off between two costs: the additional holding cost (and a loss in purchase cost as well, if future DealSavings are more than current DealSavings) if they purchased until beyond the actual deal occurrence, and the loss in DealSavings if they purchased until before the deal occurred.

Given that the consumer purchases to last until a certain time on the basis of these two costs, he or she faces two scenarios. The first is that he or she purchases to last until a certain time, and the next deal actually occurs beyond it. In this case he has to make off-deal purchases and loses on deal discounts. Thus awares could make more off-deal purchases compared with the unawares and have higher purchasing costs. However, their holding costs 
will be even lower compared with unawares than in the deterministic deal timing case. The second scenario is that the actual deal occurs before the quantity that awares purchased on the previous deal is exhausted. In this case the awares will incur extra holding costs, which they could have avoided. In addition, they will be able to purchase less on the next deal. It also could be the case that they will have too much inventory to purchase at all on the future deal. Thus, the behavior of awares will become closer to that of unawares (versus the deterministic deal timing case) in terms of quantity purchased on deal, response to deals, purchasing cost, and holding cost.

Across the two scenarios, there will be less difference in deal response between awares and unawares compared with the deterministic timing case. However, the awares will still respond to more deals compared with the unawares. Also, awares will make more off-deal purchases than unawares. As far as quantity purchased, purchasing cost, holding cost, and total cost are concerned, all the implications still will follow through by the law of averages. The exact behavior of awares will depend on how many times scenario 1 is faced versus scenario 2 , that is, how many times deals occur before versus after the time until which the awares purchase. The number of times scenario 1 occurs versus scenario 2 will depend on the specific probability distribution of the time till the next deal.

Overall, the better and more accurate the information a consumer has, the more the consumer's behavior will differ from that of one who has no awareness of future deals. Uncertainty in deal timing and deal price decrease the benefits a consumer can derive from awareness, without changing most of the implications described previously.

Another thing to consider is that consumption rate need not be constant. The effect of consumption rate on the model implications is governed by the factors that determine the consumption rate. If consumption is not a function of price or inventory, then a variable consumption rate may not make much of a difference to the model implications. If, however, consumption is a function of inventory and/or price (see Assuncao and Meyer 1993), then it is no longer reasonable to minimize cost. In this case, we may want to maximize utility when additional consumption gives additional decreasing marginal utility and cost is treated as negative utility. The model implications will now depend on the exact relationship between consumption, price, and inventory and on the exact utility function. Also, cost implications will now be irrelevant, because utility and not cost is the variable of interest. Nonetheless, irrespective of the exact formulation of the consumption and utility functions one would expect both awares and unawares to purchase more on deal and to consume more. Awares still could purchase only to last until the next deal, but they may need to purchase a larger quantity to last until the next deal because they will be consuming more. Unawares should also purchase larger quantities on deal because additional consumption gives additional utility.

We considered only consumers with no knowledge or accurate knowledge of future deals. Another type of consumer to consider is one with inaccurate knowledge of future deals. It would be useful to determine how this consumer makes purchases and updates his knowledge of deals.

We also assume that consumers shop every week. If consumers do not shop every week, but every period (e.g., every $n$ weeks), then in the model, the time to the next deal becomes the time to the next deal when they will be shopping. This will affect both aware and unaware consumers. The difference will be that aware consumers could be less likely to purchase on deals and thus their behavior will be less different from the unaware consumers.

We restrict ourselves to the consumer's problem. An extension of the work would be to build a general equilibrium model taking into account both the consumers' and the retailer's expectations and objective functions.

\section{REFERENCES}

Armstrong, Marcia, Frank M. Bass, and Ram C. Rao (1991), "Trade Dealer: A Normative Model of Retail Response to Trade Promotions," working paper, School of Management, University of Texas at Dallas.

Assuncao, Joao and Robert J. Meyer (1993), "The Rational Effect of Price Uncertainty on Sales-Price Relationships," Management Science, 39 (May), 517-35.

Bawa, Kapil and Robert W. Shoemaker (1987), "The CouponProne Consumer: Some Findings Based on Purchase Behavior Across Product Classes," Journal of Marketing, 51 (October), 99-110.

Blattberg, Robert, Thomas Buesing, Peter Peacock, and Subrata Sen (1978), "Identifying the Deal Prone Segment," Journal of Marketing Research, 15 (August), 369-77.

- Gary D. Eppen, and Joshua Lieberman (1981), “A Theoretical and Empirical Investigation of Price Deals for Consumer Durables," Journal of Marketing, 45 (Winter), 116-29.

Buyukkurt B. Kemal (1986), “Integration of Serially Sampled Price Information: Modelling and Some Findings," Journal of Consumer Research, 13 (December), 357-73.

Dickson, Peter R. and Alan G. Sawyer (1990), "The Price Knowledge and Search of Supermarket shoppers," Journal of Marketing, 54 (July), 42-53.

Gurumurthy, K. and John D.C. Little (1987), “A Pricing Model based on Perception Theories and its Testing on Scanner Panel Data," working paper, Massachusetts Institute of Technology.

Jacobson, Robert and Carl Obermiller (1990), "The Formation of Expected Future Price: A Reference Price for Forward Looking Consumers," Journal of Consumer Research, 16 (March), 420-32.

Jacoby, Jacob and Robert W. Chestnut (1978), Brand Loyalty: Measurement and Management. New York: John Wiley \& Sons, Inc.

- and David B. Kyner (1973), "Brand Loyalty Versus Repeat Purchase Behavior," Journal of Marketing Research, 10 (February), 1-9. 
Kahn, Barbara E. and Jagmohan Raju (1989), "Effects of Price Promotion on Variety-Seeking and Reinforcement Behavior," Marketing Science, 10 (Fall), 316-37.

and David C. Schmittlein (1989), "Shopping Trip Behavior," Marketing Letters, 1 (December), 55-70.

Kalwani, Manohar U. and Chi Kin Yim (1992), "Consumer Price and Promotion Expectations: An Experimental Study," Journal of Marketing Research, 29 (February), 90-100.

Krishna, Aradhna (1992), “The Normative Impact of Consumer Price Expectations for Multiple Brands on Consumer Purchase Behavior," Marketing Science, 11 (Summer), 26686.

, Imran C. Currim, and Robert W. Shoemaker (1989), "Consumer Perceptions of Promotional Activity," Journal of Marketing, 55 (April), 4-16.

Lattin, James M. and Randolph E. Bucklin (1989), "Reference Effects of Price and Promotion on Brand Choice Behavior," Journal of Marketing Research, 26 (August), 299310.

Meyer, Robert J. (1991), "Heuristics and Biases in Consumer Sequential Decision Making: Toward a Positive Theory of Intuitive Planning," working paper, University of Pennsylvania.

and J. Assuncao (1990), "The Optimality of Consumer Stockpiling Policies," Marketing Science, 9 (Winter), $18-41$.

Narasimhan, Chakravarthi S. (1988), "Competitive Promotional Strategies,” Journal of Business, 61 (4), 427-49.
Olson, Jerry C. and Jacob Jacoby (1971), "A Construct Validation Study of Brand Loyalty,” Proceedings, 6, American Psychological Association, 657-8.

Pessemier, Edgar A. (1959), “A New Way to Determine Buying Decisions," Journal of Marketing, 24 (October), 41-46.

Raju, Jagmohan S. (1990), "Offensive and Defensive Discounts: An Approach to Understanding How many Levels of Discounts to Offer," paper presented at the ORSA/TIMS Joint National Meeting, Philadelphia, November.

, V. Srinivasan, and Rajiv Lal (1990), "Effects of Brand Loyalty on Competitive Price promotion Strategy," Management Science, 36 (March), 276-304.

Simonson, Itamar and Russell S. Winer (1990), "Scanner Data and Controlled Experiments: Using Complementary Research Methods for Assessing Convergent Validity," working paper, University of California at Berkeley.

Umesh, U.N. (1989), “An Inventory Model of Deals for Consumer Nondurables," working paper, Washington State University.

Urbany, Joel E. and Peter R. Dickson (1991), "Consumer Normal Price Estimation: Market Versus Personal Standards," Journal of Consumer Research, 18 (June), 45-51.

Winer, Russell S. (1985), “A Price Vector Model of Demand for Consumer Durables: Preliminary Developments," Marketing Science, 4 (Winter), 74-90.

(1986), "A Reference Price Model of Brand Choice for Frequently Purchased Products," Journal of Consumer Research, 13 (September), 250-6. 
http://www.jstor.org

\title{
LINKED CITATIONS
}

- Page 1 of 4 -

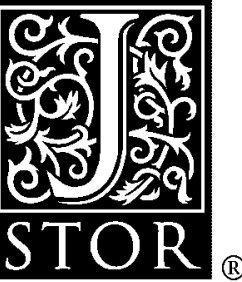

You have printed the following article:

The Effect of Deal Knowledge on Consumer Purchase Behavior

Aradhna Krishna

Journal of Marketing Research, Vol. 31, No. 1. (Feb., 1994), pp. 76-91.

Stable URL:

http://links.jstor.org/sici?sici=0022-2437\%28199402\%2931\%3A1\%3C76\%3ATEODKO\%3E2.0.CO\%3B2-7

This article references the following linked citations. If you are trying to access articles from an off-campus location, you may be required to first logon via your library web site to access JSTOR. Please visit your library's website or contact a librarian to learn about options for remote access to JSTOR.

\section{References}

The Rational Effect of Price Promotions on Sales and Consumption

João L. Assunção; Robert J. Meyer

Management Science, Vol. 39, No. 5. (May, 1993), pp. 517-535.

Stable URL:

http://links.jstor.org/sici?sici=0025-1909\%28199305\%2939\%3A5\%3C517\%3ATREOPP\%3E2.0.CO\%3B2-3

\author{
The Coupon-Prone Consumer: Some Findings Based on Purchase Behavior across Product \\ Classes \\ Kapil Bawa; Robert W. Shoemaker \\ Journal of Marketing, Vol. 51, No. 4. (Oct., 1987), pp. 99-110. \\ Stable URL: \\ http://links.jstor.org/sici?sici=0022-2429\%28198710\%2951\%3A4\%3C99\%3ATCCSFB\%3E2.0.CO\%3B2-Z
}

\section{Identifying the Deal Prone Segment}

Robert Blattberg; Thomas Buesing; Peter Peacock; Subrata Sen

Journal of Marketing Research, Vol. 15, No. 3. (Aug., 1978), pp. 369-377.

Stable URL:

http://links.jstor.org/sici?sici=0022-2437\%28197808\%2915\%3A3\%3C369\%3AITDPS\%3E2.0.CO\%3B2-2

\author{
A Theoretical and Empirical Evaluation of Price Deals for Consumer Nondurables \\ Robert C. Blattberg; Gary D. Eppen; Joshua Lieberman \\ Journal of Marketing, Vol. 45, No. 1. (Winter, 1981), pp. 116-129. \\ Stable URL: \\ http://links.jstor.org/sici?sici=0022-2429\%28198124\%2945\%3A1\%3C116\%3AATAEEO\%3E2.0.CO\%3B2-D
}


http://www.jstor.org

\section{LINKED CITATIONS}

- Page 2 of 4 -

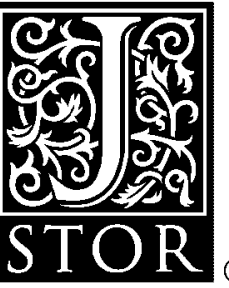

Integration of Serially Sampled Price Infromation: Modeling and Some Findings

B. Kemal Büyükkurt

The Journal of Consumer Research, Vol. 13, No. 3. (Dec., 1986), pp. 357-373.

Stable URL:

http://links.jstor.org/sici?sici=0093-5301\%28198612\%2913\%3A3\%3C357\%3AIOSSPI\%3E2.0.CO\%3B2-N

The Price Knowledge and Search of Supermarket Shoppers

Peter R. Dickson; Alan G. Sawyer

Journal of Marketing, Vol. 54, No. 3. (Jul., 1990), pp. 42-53.

Stable URL:

http://links.jstor.org/sici?sici=0022-2429\%28199007\%2954\%3A3\%3C42\%3ATPKASO\%3E2.0.CO\%3B2-6

The Formation of Expected Future Price: A Reference Price for Forward- Looking Consumers

Robert Jacobson; Carl Obermiller

The Journal of Consumer Research, Vol. 16, No. 4. (Mar., 1990), pp. 420-432.

Stable URL:

http://links.jstor.org/sici?sici=0093-5301\%28199003\%2916\%3A4\%3C420\%3ATFOEFP\%3E2.0.CO\%3B2-Q

\section{Brand Loyalty vs. Repeat Purchasing Behavior}

Jacob Jacoby; David B. Kyner

Journal of Marketing Research, Vol. 10, No. 1. (Feb., 1973), pp. 1-9.

Stable URL:

http://links.jstor.org/sici?sici=0022-2437\%28197302\%2910\%3A1\%3C1\%3ABLVRPB\%3E2.0.CO\%3B2-T

Effects of Price Promotions on Variety-Seeking and Reinforcement Behavior

Barbara E. Kahn; Jagmohan S. Raju

Marketing Science, Vol. 10, No. 4. (Autumn, 1991), pp. 316-337.

Stable URL:

http://links.jstor.org/sici?sici=0732-2399\%28199123\%2910\%3A4\%3C316\%3AEOPPOV\%3E2.0.CO\%3B2-P

\section{Consumer Price and Promotion Expectations: An Experimental Study}

Manohar U. Kalwani; Chi Kin Yim

Journal of Marketing Research, Vol. 29, No. 1. (Feb., 1992), pp. 90-100.

Stable URL:

http://links.jstor.org/sici?sici=0022-2437\%28199202\%2929\%3A1\%3C90\%3ACPAPEA\%3E2.0.CO\%3B2-X 
http://www.jstor.org

\section{LINKED CITATIONS}

- Page 3 of 4 -

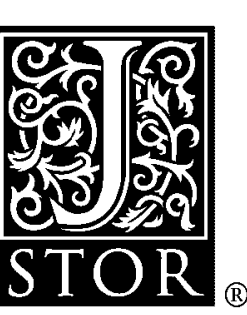

The Normative Impact of Consumer Price Expectations for Multiple Brands on Consumer Purchase Behavior

Aradhna Krishna

Marketing Science, Vol. 11, No. 3. (Summer, 1992), pp. 266-286.

Stable URL:

http://links.jstor.org/sici?sici=0732-2399\%28199222\%2911\%3A3\%3C266\%3ATNIOCP\%3E2.0.CO\%3B2-2

Consumer Perceptions of Promotional Activity

Aradhna Krishna; Imran S. Currim; Robert W. Shoemaker

Journal of Marketing, Vol. 55, No. 2. (Apr., 1991), pp. 4-16.

Stable URL:

http://links.jstor.org/sici?sici=0022-2429\%28199104\%2955\%3A2\%3C4\%3ACPOPA\%3E2.0.CO\%3B2-0

\section{Reference Effects of Price and Promotion on Brand Choice Behavior}

James M. Lattin; Randolph E. Bucklin

Journal of Marketing Research, Vol. 26, No. 3. (Aug., 1989), pp. 299-310.

Stable URL:

http://links.jstor.org/sici?sici=0022-2437\%28198908\%2926\%3A3\%3C299\%3AREOPAP\%3E2.0.CO\%3B2-9

\section{The Optimality of Consumer Stockpiling Strategies}

Robert J. Meyer; Joao Assuncao

Marketing Science, Vol. 9, No. 1. (Winter, 1990), pp. 18-41.

Stable URL:

http://links.jstor.org/sici?sici=0732-2399\%28199024\%299\%3A1\%3C18\%3ATOOCSS\%3E2.0.CO\%3B2-T

\section{Competitive Promotional Strategies}

Chakravarthi Narasimhan

The Journal of Business, Vol. 61, No. 4. (Oct., 1988), pp. 427-449.

Stable URL:

http://links.jstor.org/sici?sici=0021-9398\%28198810\%2961\%3A4\%3C427\%3ACPS\%3E2.0.CO\%3B2-F

\section{A New Way to Determine Buying Decisions}

Edgar A. Pessemier

Journal of Marketing, Vol. 24, No. 2. (Oct., 1959), pp. 41-46.

Stable URL:

http://links.jstor.org/sici?sici=0022-2429\%28195910\%2924\%3A2\%3C41\%3AANWTDB\%3E2.0.CO\%3B2-U 
http://www.jstor.org

\title{
LINKED CITATIONS \\ - Page 4 of 4 -
}

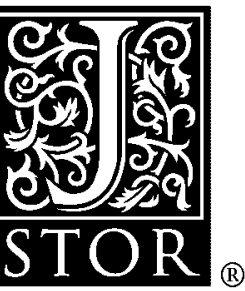

The Effects of Brand Loyalty on Competitive Price Promotional Strategies

Jagmohan S. Raju; V. Srinivasan; Rajiv Lal

Management Science, Vol. 36, No. 3. (Mar., 1990), pp. 276-304.

Stable URL:

http://links.jstor.org/sici?sici=0025-1909\%28199003\%2936\%3A3\%3C276\%3ATEOBLO\%3E2.0.CO\%3B2-A

Consumer Normal Price Estimation: Market versus Personal Standards

Joel E. Urbany; Peter R. Dickson

The Journal of Consumer Research, Vol. 18, No. 1. (Jun., 1991), pp. 45-51.

Stable URL:

http://links.jstor.org/sici?sici=0093-5301\%28199106\%2918\%3A1\%3C45\%3ACNPEMV\%3E2.0.CO\%3B2-X

A Price Vector Model of Demand for Consumer Durables: Preliminary Developments Russell S. Winer

Marketing Science, Vol. 4, No. 1. (Winter, 1985), pp. 74-90.

Stable URL:

http://links.jstor.org/sici?sici=0732-2399\%28198524\%294\%3A1\%3C74\%3AAPVMOD\%3E2.0.CO\%3B2-7

\author{
A Reference Price Model of Brand Choice for Frequently Purchased Products \\ Russell S. Winer \\ The Journal of Consumer Research, Vol. 13, No. 2. (Sep., 1986), pp. 250-256. \\ Stable URL: \\ http://links.jstor.org/sici?sici=0093-5301\%28198609\%2913\%3A2\%3C250\%3AARPMOB\%3E2.0.CO\%3B2-H
}

